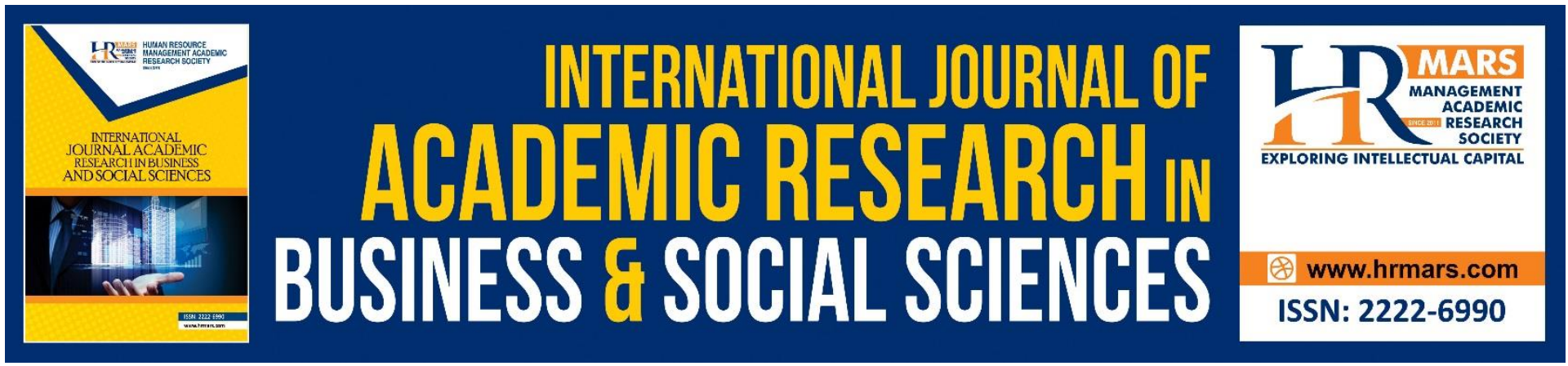

\title{
Evaluation of Pre-service Teachers' Actual use towards Augmented Reality Technology through MARLCardio
}

Nur Nabihah Mohamad Nizar, Mohd Khairezan Rahmat, Siti Maftuhah Damio

To Link this Article: http://dx.doi.org/10.6007/IJARBSS/v10-i11/8184

DOI:10.6007/IJARBSS/v10-i11/8184

Received: 04 October 2020, Revised: 23 October 2020, Accepted: 02 November 2020

Published Online: 24 November 2020

In-Text Citation: (Nizar, N. N. M., Rahmat, \& Damio, 2020)

To Cite this Article: Nizar, N. N. M., Rahmat, M. K., \& Damio, S. M. (2020). Evaluation of Pre-service Teachers' Actual use toward Augmented Reality Technology through MARLCardio. International Journal of Academic Research in Business and Social Sciences. 10(11), 1091-1101.

\section{Copyright: (c) 2020 The Author(s)}

Published by Human Resource Management Academic Research Society (www.hrmars.com)

This article is published under the Creative Commons Attribution (CC BY 4.0) license. Anyone may reproduce, distribute, translate and create derivative works of this article (for both commercial and non-commercial purposes), subject to full attribution to the original publication and authors. The full terms of this license may be seen at: http://creativecommons.org/licences/by/4.0/legalcode

Vol. 10, No. 11, 2020, Pg. 1091 - 1101

Full Terms \& Conditions of access and use can be found at http://hrmars.com/index.php/pages/detail/publication-ethics 


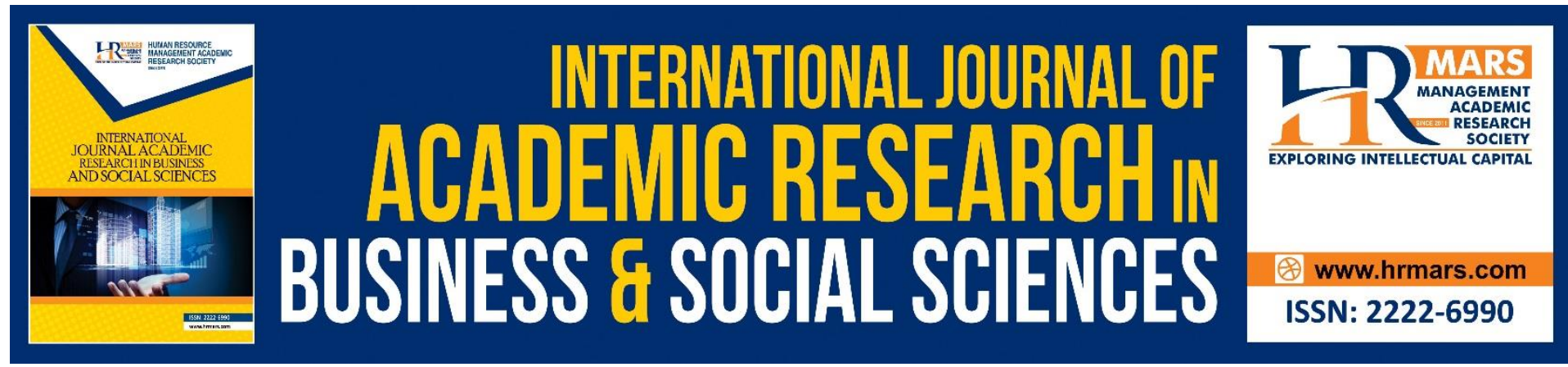

\title{
Evaluation of Pre-service Teachers' Actual use towards Augmented Reality Technology through MARLCardio
}

\author{
Nur Nabihah Mohamad Nizar, Mohd Khairezan Rahmat, Siti \\ Maftuhah Damio \\ Faculty of Education, Universiti Teknologi MARA Selangor, Kampus Puncak Alam \\ Email: nurnabihahnizar91@gmail.com
}

\begin{abstract}
Augmented reality (AR) offers an innovative learning space through an active interaction of real world with computer-assisted contextual layer of information to enhance learning experiences. AR is exciting to explore in which it can enhance a user's impression of and interaction with real and virtual world. There have been some attempts to use AR for training and educational purposes; however the potential of AR in education remains unexplored as it seen as a future of education. In addition to the lack of information about AR in education especially in Malaysia, there is also inadequate information about the influencing factors in determining students' decision to use AR in their learning process. Thus, the present paper aims to evaluate factors that might influence pre-service teachers' decision in using $A R$ technology through Mobile Augmented Reality Learning Cardiovascular (MARLCardio). A selfdesigned MARLCardio was used as an experimental tool in data collection process. All respondents were given a chance to explore an AR features in MARLCardio before they responds to a web-based survey. The respondents of the study are 459 pre-service teachers at three public universities in Malaysia with different field of study. All data gathered from the questionnaire was analysed using path coefficients in SmartPLS. As a result of this investigation, results revealed that attitude (ATT) is the main factor in determining the actual use of MARLCardio. Surprisingly, field of study (FOS) was not found as a moderating effect of any relationship.
\end{abstract}

Keywords: Augmented Reality, Technology Adoption Model

\section{Introduction}

The advance of digital technology has now made major changes to the world and students began to gaze at another learning opportunity by using mobile devices (Issham, Siti Norbaya, and Gunasegaran, 2016). The acceptance of mobile devices usage in learning is relatively high as it allows students to obtain learning resources anytime and anywhere informally by using mobile devices via Internet.

In the past few years, several researchers have started exploring the benefits of augmented reality (AR) which can be accessed using mobile devices, called Mobile Augmented Reality (Chung, 2017; Hanafi et al., 2016; Lazim and Abd Rahman, 2015; Goutzioupas \& lordanides, 
2013). AR offers an innovative learning space through an active interaction of superimposing digital contents into the real context to enhance learning experiences (Azuma, 1997). Initially, $A R$ has been widely exposed in the gaming and entertainment industry. Now, the great potentials of $A R$ has been discovered in education (Lee et al., 2018; Wojciechowski and Cellary, 2013; Serio, Ibanez and Kloos, 2013). Basically, the idea of AR has existed in the1950s but people started to discover the potential of AR in education after about half a century, mainly in 2009. Within that period, the potential of $A R$ in education remains underexplored (Serio, Ibanez and Kloos, 2013 ) and even if it is explored, it still at infancy stage in Malaysia (Mat-jizat et al., 2016). Given these scenario, it is time to see the growth of AR implementation in Malaysian education sector.

In Malaysia, there are limited published article reviewing AR in Education (Lazim and Abd Rahman, 2015; Mat-jizat et al., 2016; Abd Majid and Kamarudin, 2014). In addition, there are also limited published AR sources that can be accessed for learning purposes. AR is exciting as it can enhance a user's impression. The information obtained from the virtual objects helps a user to comprehend real-world tasks easily. Due to that reason, there have been some attempts to use AR for training and educational purposes in different scope of study (Lazim and Abd Rahman, 2015; Mat-jizat et al., 2016; Allen, 2016). In addition to the lack of information on AR in education, especially in the local context of Malaysia, there is also inadequate information explaining the predictor factors that might influence students' decision to use AR in learning. It is an important issue that should be highlighted to ensure that AR can be extensively used for education purposes. Hence, the present study attempts to evaluate the influencing factors towards pre-service teachers' decisions to use AR by using Mobile Augmented Reality Learning Cardiovascular (MARLCardio) as an experimental tool. The discussion related to past studies and the lack of information on the use of AR in Malaysia have provided a strong rationale, as well as emphasize the grounds to conduct the present study.

\section{Research Model}

This section addresses the research model that been formulated based on past theories and technology adoption model in order to evaluate pre-service teachers' actual use toward MALRCardio.

\section{Performance Expectancy (PE)}

In this study, performance expectancy (PE) was refer to the degree of pre-service teacher to believe that using MARLCardio will influence their decision towards the use of MARLCardio in learning process. PE bring a same meaning with perceived usefulness as presented in Technology Acceptance Model (TAM) Davis, 1989). Despite clearly being stated in UTAUT model (Venkatesh, Thong and Xu, 2012), several studies have acknowledged PE as one of the predictors of individuals' believe in use of technology (Albashrawi et al., 2017; Maruping et al., 2016; Baydas and Yilmaz, 2016; Anastasiou et al., 2013).

Most previous literatures show consistencies on their result that whenever each time an effect on attitude is found, it is positive (Nysveen and Pedersen, 2014; Chang, Yan and Tseng, 2012; Isaias et al., 2017). Study conducted in Guyana found that PE have a positive effects on ATT in explaining the mobile learning adoption in higher education (Thomas, Singh and Gaffar, 2013). Similar finding was reported in AR scope of study, whereas results show that learners' PE significantly influence their ATT in learning process (Wojciechowski and Cellary, 2013). In 
spite of the consistencies of result found in the literature, this study looks into the following hypothesis about effect on ATT to embrace:

$\mathrm{H}_{1}(\mathrm{a})$ : The pre-service teachers' PE has a significant influence on their ATT towards the use of MARLCardio in learning process.

The relationship between PE and the actual use (AU) of technology has been recognized previously in Motivational Model (MM) under construct of extrinsic motivation. It was reported that perceived usefulness is one of the predictors towards student's usage of Facebook (Teo, 2014). Additionally, a study which examined consumers' influencing factor toward the use of online health information service also found perceived usefulness as one of the strong indicator in predicting their integration of the services (Mou, Shin and Cohen, 2016). Given these justifications, the next hypothesis was formulated as:

$\mathrm{H}_{1}(\mathrm{~b})$ : The pre-service teachers' PE has a significant influence on their AU of MARLCardio in learning process.

\section{Effort Expectancy (EE)}

Unified theory of acceptance and use of technology (UTAUT) adoption model has theorized effort expectancy (EE) as one of the factor influencing an individuals' use of technology (Venkatesh, Thong and $\mathrm{Xu}, 2012$ ). Within the same meaning, EE also be presented as perceived ease of use in the TAM (Davis, 1989) and decomposed theory of planned behavior (DPTB) (Li, Chung and Fiore, 2017). Through the different name of constructs, EE and perceived ease of use can be define as a degree of an individuals to belief that they will be free of effort while using technology (Davis, 1989). In this paper, EE was therefore defined as the extent of pre-service teachers to belief that they will be free of effort when using MARLCardio in learning process.

As verified by TAM, an individuals' EE has a positve relationship towards their attitude (ATT) in use of technology. This relationship has been tested and proven to have a strong impact on many previous studies (Wojciechowski and Cellary, 2013; Chang, Yan and Tseng, 2012; Thomas, Singh and Gaffar, 2013). Additionally, it has now been suggested that the pleasure and effortless of using the system will help to build consumers ATT towards the usage (Li, Chung and Fiore, 2017). These findings therefore suggest that an individuals' EE has influencing their ATT to use technology. Thus, this present study carry on the subsequent hypothesis :

$\mathrm{H}_{2}(\mathrm{a})$ : The pre-service teachers' EE has a significant influence on their ATT towards the use of MARLCardio in learning process.

The emergent factors that influence an individuals' decision towards AU of technology have recognized $\mathrm{EE}$ as one of the conceivable predictor. It has been verified by numbers of scholars in their research's' findings (Bharati and Srikanth, 2018; Guest et al., 2018; Shang and Wu, 2017). All these findings indicate that the percentage use of proposed technology is higher when a user feels it is easy to use. On the contrary, several studies revealed that there is no positive significant relationship between EE and AU of proposed technology (Paulo et al., 2017; Madigan et al., 2017; Maillet, Mathieu and Sicotte, 2015). Given these inconsistent research findings, this present study will tested the following hypothesis :

$\mathrm{H}_{2}(\mathrm{~b})$ : The pre-service teachers' EE has a significant influence on their AU of MARLCardio in learning process. 


\section{Attitude (ATT)}

ATT can be defined as an effect, and action operates partly through internal standards and evaluation reactions to an individuals' behaviour (Bandura, 2001). The evaluation of reactions come in the form of positive and negative. Thus, ATT in the present study was defined as the degree to which students' have a positive or negative towards the actual use of MARLCardio in learning process. Responses from 330 social networking sites (SNS) found that users' ATT towards AU of mobile SNS is positively significant (Ha et al., 2015).Similar finding was also been reported whereas the user's positive attitude affected their decision to use the mobile purchase application (Gao, Waechter and Bai, 2015). In other words, ATT will determine an individual's action to be taken. Therefore, the following hypothesis was formulated as:

$\mathrm{H}_{3}(\mathrm{a})$ : The pre-service teachers' ATT has a significant influence on their AU of MARLCardio in learning process.

\section{Field of Study (FOS)}

The penetration of AR has attracted the attention of researchers from various field of study (FOS) in recent years. Integration of $A R$ in education has been explored in field of early childhood [34], science education (Salmi, Thuneberg and Vainikainen, 2016), tourism (Tussyadiah, Jung and Dieck, 2017) mathematics (Saloano et al., 2017) and psychology (Giglioli et al., 2015). Given these research findings, it's proven that the implementation of AR in education has expanded to varying field of study. With regards of this study, FOS will be taken as a moderator variable since the respondents come from three different field of study. The inclusion of FOS into a moderator variable was undertaken in order to have a better understanding about pre-services teacher use of MARLCardio since the participants comes from various field of study. Therefore, the present study proposed the following hypothesis: $\mathrm{H}_{4}(\mathrm{a})$ : The relationship between higher education students' PE towards the AU of MARLCardio in learning process is moderated by their field of study

$\mathrm{H}_{4}$ b): The relationship between higher education students' EE towards the AU of MARLCardio in learning process is moderated by their field of study

\section{Methodology \\ Sample}

The study involved 459 participants of pre-service teachers from three different field of study which are science stream, social sciences and Technical and Vocational Education and Training (TVET). This study has been conducted at three public universities in Malaysia.

\section{Data Collection Procedure}

Mobile Augmented Reality Learning Cardiovascular (MARLCardio) is an experimental tool used in this study. It comes in two versions of AR-objects which are MARLCardio booklet and MARLCardio application. In MARLCardio booklet there are serveral marker images in the form of physical object. Users can explore the AR content in MARLCardio booklet by scanning the marker image in the booklet by using MARLCardio app. Both MARLCardio booklet and MARLCardio app should be used together to get AR experiences. Figure 1 provides an AR installation of MALRCardio for better understanding.

\section{Fig. 1. MARLCardio Installation}




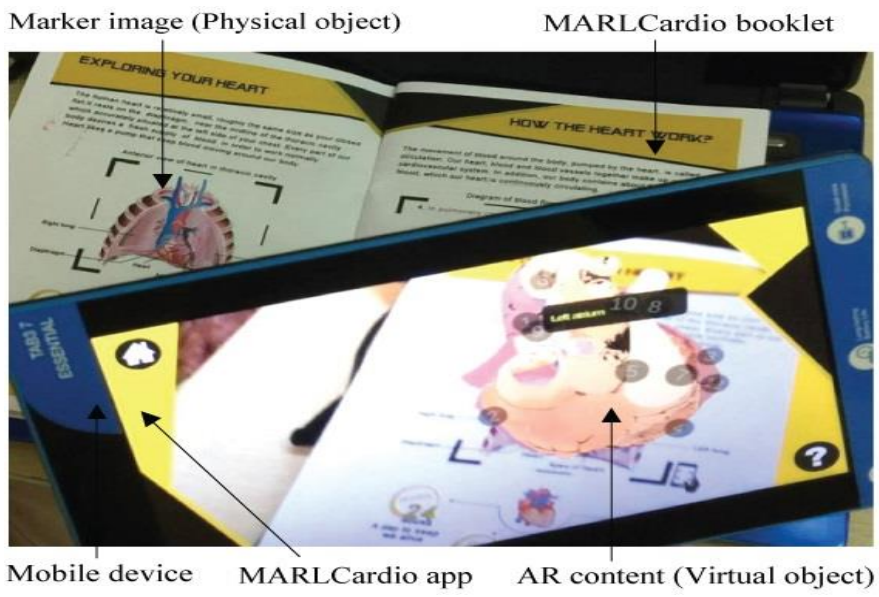

MARLCardio booklet was distributed to each of the participants. It is to ensure that all participants had an opportunity to access the AR content in MARLCardio booklet. The participants were asked to download MARLCardio app through Google Play or iOS to assist them in exploring AR content in MARLCardio booklet by using their own mobile device. The participants browse the content in MARLCardio booklet and start scanning AR image using MARLCardio app to get more information on particular topic. Responses from the participants after using MARLCardio are tested in order to determine influencing factors towards the actual use of MARLCardio throughout a web-based survey.

\section{Measures and Questionnaire}

The items in each constructs were measures using validated items from previous study (Davis, 1989; Venkatesh, Thong and Xu, 2012). Responses to all questions were measured using a 4point likert scale ranging from "strongly disagree (1)" to "strongly agree (4)". The questionnaire has undergone a pilot testing with 72 students to examine the practicability of an items.

\section{Statistical Analysis}

Data collection has been coded into IBM SPSS Statistics 21 for reliability analysis prior to the path coeeficients analysis. In order to test the hypotheses SmartPLS 3.0 was employed.

\section{Findings}

\section{Reliability Analysis}

Reliability analysis was conducted for each variables using cronbach alpha. It is to determine the internal consistency reliability coefficient for each item in constructed variables. It has been suggested that value of alpha, 0.50 are acceptable while scores more than 0.70 indicated great reliability (White et al., 2012). Reliability analysis in Table 1 provide confirmatory evidence that those constructs have high reliability as the value is greater than 0.70 .

TABLE I. THE CRONBACH ALPHA VALUE

\begin{tabular}{|l|l|}
\hline Variables & Cronbach Alpha \\
\hline $\begin{array}{l}\text { Performance Expectancy } \\
\text { (PE) }\end{array}$ & 0.878 \\
\hline Effort Expectancy (EE) & 0.847 \\
\hline Attitude (ATT) & 0.890 \\
\hline Actual Use (AU) & 0.945 \\
\hline
\end{tabular}




\section{Research Hypotheses}

Consistence bootstrapping was employed by using SmartPLS to determine the statistical significance of the path coefficient and calculate the $p$-values in this study. The calculated path coefficients as shown in Table II.

As a results of path coefficients, data revealed that PE $(p=0.003)$ and EE $(p=0.016)$ are predictors in determining pre-services teachers' ATT in using MARLCardio. Therefore, the $\mathrm{H}_{1}(\mathrm{a})$ and $\mathrm{H}_{2}(\mathrm{a})$ hypotheses was supported. Results also indicated that PE, EE and ATT had a positive relationship towards AU of MARLCardio since $p$-value $<0.05$. Hence, the $H_{1}(b), H_{2}(b)$ and $\mathrm{H}_{3}$ hypotheses was supported. On the other hand, statistical outcomes caused the exclusion of FOS as a moderator due to the higher number of $p$-value.

TABLE II.

PATH COEFFICIENTS

\begin{tabular}{|l|l|l|l|l|}
\hline Hypotheses & $\begin{array}{l}\text { Hypothesized } \\
\text { Path }\end{array}$ & $\begin{array}{l}\text { T } \\
\text { Statistics }\end{array}$ & $\begin{array}{l}\text { P } \\
\text { Values }\end{array}$ & $\begin{array}{l}\text { Accepted/ } \\
\text { Rejected }\end{array}$ \\
\hline $\mathrm{H}_{1}(\mathrm{a})$ & PE $>$ ATT & 2.939 & 0.003 & Accepted \\
\hline $\mathrm{H}_{1}(\mathrm{~b})$ & PE $>$ AU & 3.042 & 0.002 & Accepted \\
\hline $\mathrm{H}_{2}(\mathrm{a})$ & EE $>$ ATT & 2.408 & 0.016 & Accepted \\
\hline $\mathrm{H}_{2}(\mathrm{~b})$ & EE $>$ AU & 3.074 & 0.002 & Accepted \\
\hline $\mathrm{H}_{3}$ & ATT $>$ AU & 4.300 & 0.000 & Accepted \\
\hline $\mathrm{H}_{4}(\mathrm{a})$ & PE $>$ FOS $>$ AU & 1.147 & 0.251 & Rejected \\
\hline $\mathrm{H}_{4}(\mathrm{~b})$ & EE $>$ FOS $>$ AU & 1.407 & 0.160 & Rejected \\
\hline
\end{tabular}

The structural models in determining the actual use of pre-service teachers in using AR through MARLCardio are revealed in Figure. 2. Output of $R^{2}$ represents value for any predicted variables. Data indicated that $62.0 \%$ variance in ATT that can be explained by PE and EE. Additionally, three predicted variables which are PE, EE and ATT highly explain $80.3 \%$ of the variance in AU.

Fig. 2. Structural model in explaining the Actual Use $(A U)$ of MARLCardio

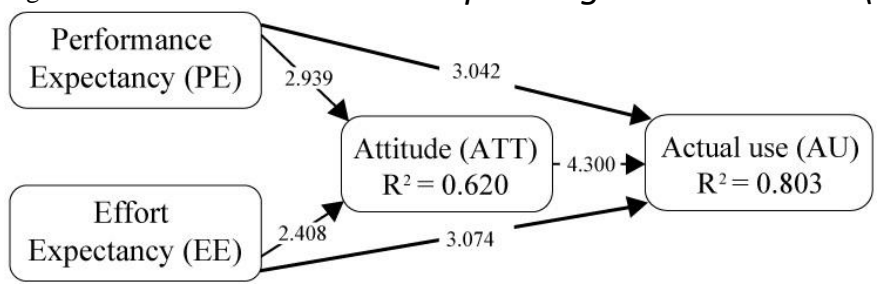

\section{Conclusion}

Surprisingly, FOS did not bring any moderated effect in this study. With an exception of FOS as moderator, it can be concluded that regardless what is pre-service teachers' FOS, it did not affect their AU of MARLCardio. Interestingly, eventhough MARLCardio promotes a content that slightly close to science stream, but it does not show any effect among those who are from social science and TVET.

The present paper aims to validate the factors affecting pre-service teacher's decision in using AR for learning purpose. The result revealed that PE, EE and ATT are an important variables that will determine the use of AR. In other words, MARLCardio provide beneficial knowledge for them and they might think that AR can help in expanding their learning process. Although $A R$ is still at a fancy stage in Malaysia, but it has proven that AR can easily being adapted since 
there are positive relationship between $E E$ and $A U$. In addition, pre-service teachers also show a positive ATT while using MARLCardio. To sum up, ATT is a main predictor in determine AU of MARLCardio as the relationship was highly significant compare to PE and EE.

Looking at these finding scenario, it might be because of pre-service teachers comes from generation $Z$. This generation is generally being labeled as a generation who have explored the use of Internet since young age and are comfortable with technology use. Participants of this research are between 20 years old to 24 years old in range of age who are known as to be the most high-use Internet and mobile devices (Malaysian Communications and Multimedia Commision, 2015). Due to that reasons, it was predictable that they can easily adapt and tend to favour MARLCardio. Expected that when they are exposed to AR, they can get some ideas to integrate it in the classroom and able to use it as one of an instructional tool in future. Therefore, it is expected that there are potential of $A R$ to be implemented in education.

In order to get better understanding in explaining $A U$ of $A R$, further research can be conducted by adding more possible predictors such as social influences and facilitation condition as drawn in UTAUT model. To ensure the stability of AR, continuance intention variable in expectation-comfirmation model (ECM) (Bhattacherjee, 2001) might be one good predictor to be added. Continuance intention helps to get a clearer picture in understanding users decision to keep using certain technology. In addition, pre-service teachers' experience in using AR can also be considered as a moderator since there are past studies which had confirmed the positive moderating effect (Pappas, 2014; Tarhini, Hone and Liu, 2014). Considering the nature of AR technology in Malaysia, the exposure is still at initial process especially in education setting. Hence, many researches of AR in education need to be done to get a better understanding.

\section{Acknowledgment}

This research is ostensibly supported by the Institute of Research Management \& Innovation (IRMI), UiTM under 'Geran Penyelidikan Penyelia' (GIP)

\section{References}

Anastasiou, A., Valkanos, E., Simos, G., Montgomery, A., \& Karamitropoulos, L. (2013). Measuring Elementary School Principals' and Vice-Principals' Competence: Adjustment and Evaluation of Kelly Glodt's Instrument in Greece. Multilingual Academic Journal of Education and Social Sciences, 1(1), 50-69.

Issham, I., Norbaya, S. A., \& Gunasegaran, T. (2016). Mobile learning in Malaysian universities : Are students ready ? International Journal of Interactive Mobile Technologies, 17-23.

Chung, N., Lee, H., Kim, J.-Y., \& Koo, C. (2017). The Role of Augmented Reality for ExperienceInfluenced Environments: The Case of Cultural Heritage Tourism in Korea. Journal of Travel Research, 1-17.

Goutzioupas, G., \& Iordanides, G. (2013). “Micropolitics” and Secondary Education Teachers' Evaluation in Greece. Multilingual Academic Journal of Education and Social Sciences, $1(1), 70-85$.

Hanafi, H. F., Said, C. S., Ariffin, A. H., Zainuddin, N. A., \& Samsuddin, K. (2016). Using a collaborative mobile augmented reality learning application (coMARLA) to improve student learning. International Engineering Research and Innovation Symposium (pp. 1-9). Bristol: IOI Publishing. 
Lazim, N. A., \& Abd Rahman, K. A. (2015). State-of-the-art responses on augmented reality application in Malaysia. Alam Cipta, 29-34.

Azuma, R. (1997). A survey of augmented reality. Teleoperators and Virtual Environments, 355-385.

Lee, K.-F., Wu, M.-S., Hsieh, H.-C., \& Chin, K.-Y. (2018). Augmented reality supported mobile self-guided system for enhancing authentic learning activities. Int. J. Cognitive Performance Support, 117-131.

Wojciechowski, R., \& Cellary, W. (2013). Evaluation of learners' attitude towards learning in ARIES augmented reality environments. Computers \& Education, 570-585.

Serio, D. A., Ibanez, M. B., \& Kloos, C. D. (2013). Impact of an augmented reality system on students' motivation for visual art course. Computer \& Education, 586-596.

Mat-jizat, J., Osman, J., Yahaya, R., \& Samsudin, N. (2016). The use of augmented reality (ar) among tertiary level students : Perception and experience. Asian Journal of Sustainable Business and Society, 42-49.

Abd Majid, N. A., \& Kamarudin Husain, N. (2014). Mobile learning application based on augmented reality for science subject : Isains. Journal of Engineering and Applied Sciences, 1455-1460.

Allen, K. R. (2016). Building bridges between the virtual and real: A study of augmented and virtual Realities in the museum space and the collaborations that produce them. United States: ProQuest LLC.

Davis, F. D. (1989). Perceived usefulness, perceived ease of use, and user acceptance of information technology. Management Information Systems Research Center,, 319340.

Venkatesh, V., Thong, J. Y., \& Xu, X. (2012). Consumer acceptance and use of information technology : Extending the unified theory of acceptance and use of technology. Mis Quarterly, 157-178.

Albashrawi, M., Kartal, H., Oztekin, A., \& Motiwalla, L. (2017). The impact of subjective and objective experience on mobile banking usage : An analytical approach. Proceedings of the 50th Hawaii International Conference on System Sciences, 1161-1171.

Maruping, L. M., Bala, H., Venkatesh, V., \& Brown, S. A. (2016). Going beyond intention : integrating behavioral expectation into the unified theory of acceptance and use of technology. Journal of the association for information science and technology, 1-15.12

Baydas, O., \& Yilmaz, R. M. (2016). Pre-service teachers' intention to adopt mobile learning : A motivational model. British Journal of Educational Technology, 1-15.

Nysveen, H., \& Pedersen, P. E. (2014). Consumer adoption of RFID-enabled services. Applying an extended UTAUT model. Information systems frontiers, 1-22.

Chang, C.-C., Yan, C.-F., \& Tseng, J.-S. (2012). Perceived convenience in an extended technology acceptance model : Mobile technology and English learning for college students. Australasian Journal of Educational Technology, 809-826.

Isaias, P., Reis, F., Coutinho, C., \& Lencastre, J. A. (2017). Empathic technologies for distance/mobile learning : An emperical research based on UTAUT. Interactive technology and Smart Education, 1-20.

Thomas, T. D., Singh, L., \& Gaffar, K. (2013). The utility of the UTAUT model in explaining mobile learning adoption in higher education in Guyana. International Journal of Education and Development using Information and Communication Technology (IJEDICT), 71-85. 
Teo, T. (2014). Modelling facebook usage among universities students in Thailand: The role of emotional attachment in an extended technology acceptance model. Interactive Learning Environments, 1-15.

Mou, J., Shin, D.-H., \& Cohen, J. (2016). Understanding trust and perceived usefulness in the consumer acceptance of an e-service : a longitudinal investigation. Behaviour \& Information Technology, 1-16.

Taylor, S., \& Todd, P. A. (2001). Understanding information technology usage : A test of competing models. Information System Research, 144-175.

Li, R., Chung, T.-L., \& Fiore, A. M. (2017). Factors affecting current users' attitude towards eauctions in China: An extended TAM study. Journal of Retailing and Consumer Services, 19-29.

Bharati, V. J., \& Srikanth, R. (2018). Modified UTAUT2 model for m-learning among. Int. J. Learning and Change, 5-19.

Guest , W., Wild, F., Vovk, A., Lefrere, P., Klemke, R., Fominykh, M., \& Kuula, T. (2018). A Technology Acceptance Model for Augmented Reality and Wearable Technologies. Journal of Universal Technology Science, 192-219.

Shang, D., \& Wu, W. (2017). Understanding mobile shopping consumers' continuance intention. Industrial Management \& Data Systems, 213-227.

Paulo, M. M., Rita, P., Oliveira, T., \& Moro, S. (2017). Understanding mobile augmented reality adoption in a consumer context. Journal of Hospitality and Tourism Technology, 1-17.

Madigan, R., Louw, T., Wilbrink, M., Schieben, A., \& Merat, N. (2017). What influences the decision to use automated public transport? Using UTAUT to understand public acceptance of automated road transport systems. Transportation Research Part F, 5564.

Maillet, E., Mathieu, L., \& Sicotte, C. (2015). Modeling factors explaining the acceptance, actual use and satisfaction of nurses using an Electronic Patient Record in acute care settings: An extension of the UTAUT. International Journal of Medical Informatics, 3647.

Bandura, A. (2001). Organisational application of social cognitive theory. Australian Journal of Management, 275-302.

Ha, Y. W., Kim, J., Libaque-Saenz, C. F., Chang, Y., \& Park, M.-C. (2015). Use and gratifications of mobile SNSs : Facebook and KakaoTalk in Korea. Telematics and Informatics, 425438.

Gao, L., Waechter, K. A., \& Bai, X. (2015). Understanding consumers' continuance intention towards mobile purchase : A theoretical framework and empirical study - A case of China. Computer in Human Behaviour, 249-262.

Huang, Y., Li, H., \& Fong, R. (2015). Using augmented reality in early art education : a case study in Hong Kong kindergarten. Early child development and care, 1-16.

Salmi, H., Thuneberg, H., \& Vainikainen, M.-P. (2016). Making the invisible observable by Augmented Reality in informal science education context. International Journal of Science Education, 1-17.

Tussyadiah, I., Jung, T. H., \& Dieck, M. T. (2017). Embodient of wearable augmeted reality technology in tourism experiences. Journal of Travel Research, 1-15.

Solano, A., Ugalde, F., Gomez, J., \& Sanchez, L. (2017). An augmented reality application to enhance the children's engagement in an early development method for mathematics literacy. Advances in Intelligent Systems and Computing , 405-414. 
Giglioli, I. C., Pallavicini, F., Pedroli, E., Serino, S., \& Riva, G. (2015). Augmented reality : A brand new challenge for the assessment and treatment of psychological disorders. Computational and Mathematical Methods in Medicine, 1-12.

White, G., Cordato, D., O'Rourke, F., Mendis, R., Ghia, D., \& Chan, D. (2012). Validation of the stroke rehabilitation motivation scale: A pilot study. Asian Journal of Gerontology \& Geriatrics , 80-87.

Malaysian Communications and Multimedia Commision. (2015). Komunikasi \& Multimedia: Buku Maklumat Statistik. Selangor: Malaysian Communications and Multimedia Commision (MCMC).

Bhattacherjee, A. (2001). Understanding information systems continuance : An expectationcomfirmation model. MIS Quarterly, 351-370.

Pappas, I. O., Pateli, A. G., Giannakos, M. N., \& Chrissikopoulos, V. (2014). Moderating effects of online shopping experience on customer satisfation and repurchase intentions. International Journal of Retail \& Distribution Management, 187-204.

Tarhini, A., Hone, K., \& Liu, X. (2014). The effects of individual differences on e-learning users' behaviour in developing countries: A structural equation model. Computer in Human Behavior, 153-16. 